\title{
ARTIGO
}

\section{GOVERNO ABERTO, TRANSPARÊNCIA E GOVERNO ELETRÔNICO NAS CÂMARAS MUNICIPAIS PARAIBANAS: UM ESTUDO MULTICASO ${ }^{1}$}

\author{
Sérvulu Mário de Paiva Lacerda ${ }^{2}$ \\ Diogo Henrique Helal
}

\begin{abstract}
RESUMO
O artigo busca compreender como funciona o atual estágio das ações de transparência e governo eletrônico no Poder Legislativo Municipal paraibano. Analisa, em particular, o acesso à informação, participação e colaboração da sociedade em processos políticos e deliberativos. Como método, o artigo adotou a abordagem mista. A primeira etapa foi quantitativa, a partir da verificação, em trinta câmaras municipais selecionadas a partir do tamanho populacional do município, da efetividade da transparência passiva, por meio da aplicação de Escala Brasil Transparente, que cobre aspectos da regulamentação do acesso à informação e da existência do Serviço de Informação ao Cidadão. Na parte qualitativa, foram selecionadas seis Câmaras Municipais, onde se realizou entrevistas com as autoridades de monitoramento e seus presidentes. Os resultados indicaram que das trinta câmaras pesquisadas, 23 não regulamentaram a Lei de Acesso à Informação. Identificou-se, por fim, que os portais dos Poderes Legislativos paraibanos se preocupam em disponibilizar informações, de modo simplista, e que a accountability e governo aberto são objetivos ainda distantes.
\end{abstract}

Palavras-chave: Governo aberto. Transparência. Governo eletrônico.

\section{INTRODUÇÃO}

Um dos propósitos das reformas do Estado em várias partes do mundo tem sido fortalecer a participação e colaboração do cidadão nos processos políticos e deliberativos (BRESSER-PEREIRA; SPINK, 1998). Um dos conceitos emergidos dessas reformas foi o de "governo aberto", proposto na Grã-Bretanha na década de 1980, que tem como base a abertura de dados sem precedentes e um sistema de transparência, participação e colaboração pública que promove a eficácia e eficiência governamental (MENDIETA, 2013).

Para Ramírez-Alujas (2011), governo aberto é um meio para reformar a sociedade e o Estado, que passam de um modelo organizativo vertical para uma rede de colaboração e

\footnotetext{
${ }^{1}$ Como citar este artigo: LACERDA, Sérvulu Mário de Paiva; HELAL, Diogo Henrique. Governo aberto, transparência e governo eletrônico nas câmaras municipais paraibanas: um estudo multicaso. ForScience: revista científica do IFMG, Formiga, v. 7, n. 1, e00472, jan./jun. 2019. DOI: 10.29069/forscience.2019v7n1.e472.
}

${ }^{2}$ Autor para correspondência: Sérvulu Mário de Paiva, e-mail: servulu@ gmail.com 
atenção básica de assuntos públicos, individualizados por setores da gestão integral, a fim de criar compromissos transversais e gerar valor público em colaboração. Nesse sentido, o objetivo do governo aberto seria tornar a administração mais sensível às necessidades e às prioridades de seus cidadãos e oferecer a eles, às empresas e às organizações da sociedade civil mais acesso à informação governamental (GAVELIN; BURALL; WILSON, 2009).

Governo aberto é um conceito amplo que incorpora questões de transparência, accountability, participação cidadã e inovação tecnológica. Para Raupp e Pinho (2013) tais questões são difíceis de serem implementadas no âmbito municipal; segundo esses autores, as câmaras municipais se estruturam em bases patrimonialistas de dominação política, resultantes de uma posição que faz prevalecerem na sociedade valores pessoais em detrimento dos coletivos ou racionais. Tal contexto se configura em um cenário totalmente desfavorável à transparência e à participação social.

O governo eletrônico surge assim como instrumento para melhorar a qualidade dos serviços e garantir valores democráticos (SANTOS et al., 2013). Dessa forma, pode ter papel fundamental na concretização da participação da sociedade no governo e no controle social, podendo contribuir para a construção de um governo aberto.

Cumpre lembrar que apesar de promissor, a efetivação do governo eletrônico enfrenta alguns importantes desafios, de acordo com Lima-Filho et al. (2011, p. 27), a saber:

[...] a incipiente participação popular; a dificuldade em encontrar linguagem compreensível na publicização das informações; a falta de confiança nos representantes; a ausência entre governantes e governados; o baixo grau de escolaridade de grande parte da população e a falta e a assimetria das informações.

Diante deste contexto, este artigo busca compreender como funciona o atual estágio das ações de transparência e governo eletrônico no Poder Legislativo Municipal paraibano. Analisa, em particular, o acesso à informação, participação e colaboração da sociedade em processos políticos e deliberativos.

\section{GOVERNO ABERTO}

Segundo Bingham e Foxworthy (2012), as iniciativas de Governo Aberto baseiam-se em três ideias: a transparência, que promove responsabilização (accountability); a participação, que melhora eficácia governamental e qualidade de tomar decisões; e a colaboração, que incorpora cidadãos nas ações do governo. 
Para Cobo (2013), o conceito de governo aberto ainda está em construção, mas há uma série de ideias reflexivas para reconstruí-lo através de novas formas que poderiam aumentar e melhorar a capacidade das sociedades democráticas para lidar, de forma eficaz, sustentável e equitativa, com questões de interesse comum, ou seja, se um governo realiza adequadamente as ideias de abertura, poderá melhorar a democracia e a inteligência cívica, mantendo seus custos em níveis aceitáveis.

Importante ressaltar a análise dos fundamentos teóricos do conceito de governo aberto de Mendieta (2013). Para o autor, por trás do conceito de governo aberto existem teorias sobre o governo promotor de bem-estar, por meio da capacidade regulatória, o governo transparente, que presta contas, o governo participativo, promotor de civismo, e o governo eficiente, colaborador e gerador de conhecimento.

Essas quatro correntes se fundem no conceito complexo de governo aberto, no qual se acrescenta o fator-chave das novas tecnologias da informação e comunicação, que permitem que boa parte de suas práticas se realizem por meio da internet.

Para Mariscal (2013), no Brasil há algumas barreiras a respeito dos padrões da Open Government Partnership (OGP) relacionadas à cultura do secreto, tão presente na administração pública. Nesse cenário, a demanda do cidadão não é vista como legítima, mas como problema ou incômodo.

Considera-se também que a poliarquia institucionalizada no país afeta a implementação das ações do governo aberto. Nesse contexto, para dirimir a cultura do secreto, há planos de ação de governo aberto, com foco nas correntes teóricas do "governo transparente que presta conta" juntamente com o "governo participativo e promotor de civismo" (OPEN GOVERNMENT PARTNERSHIP, 2013).

Este artigo considera que transparência e governo eletrônico são pontos-chave para o desenvolvimento e a implementação do governo aberto, itens que trataremos a seguir.

\section{TRANSPARÊNCIA}

O direito do cidadão ao acesso à informação em relação às questões públicas não é recente. Cruz et al. (2012), contudo, destacam que a preocupação com a transparência só foi retomada de forma relevante no final de século XX, com a implementação da administração gerencial.

Para Amorim e Almada (2014), outra questão que tornou relevante o tema da transparência foi o surgimento das tecnologias da informação e comunicação (TIC), 
especialmente a internet. Os autores referem que, por meio das TIC, pesquisadores intensificaram os estudos na área com a premissa das reais possibilidades de aprimorar os princípios democráticos, que incluem acesso à informação clara e de boa qualidade para manter o cidadão tão bem informado quanto o gestor público.

Contribuir para que cidadãos tenham acesso a informações sobre assuntos públicos é o marco de uma democracia que os torna conscientes quanto a ser agentes ativos das políticas públicas, a contribuir com o controle social das atividades dos agentes públicos e prevenir a corrupção. Essa relação entre transparência e viabilização do controle social como ferramenta de combate à corrupção foi confirmada na Convenção das Nações Unidas contra a Corrupção (BRASIL, 2013).

Nesse debate sobre transparência, estudos apresentam uma divisão conceitual entre transparência opaca e clara. Para Fox (2007) e Angélico (2012), a transparência opaca dissemina informações que, na prática, não revelam como as Instituições funcionam, enquanto a transparência clara envolve programas e práticas de acesso à informação que revelam informações úteis e confiáveis sobre desempenho institucional. Nesse sentido, a transparência opaca cumpre a função de evitar autêntica participação da sociedade.

Avançando no debate, ambos os autores buscam relacionar transparência à accountability, considerando a transparência clara, e accountability hard, como transparência ideal.

Cumpre lembrar que transparência pode ser também classificada em: ativa e passiva. A ativa é entendida como informações que são disponibilizadas proativamente, como a publicação de indicadores de desempenho do serviço público; balanços institucionais, cuja disponibilidade tem sido cada vez mais exigida em página de web de informações sobre serviços prestados, dados e valores mais relevantes da gestão; indicadores de desempenho, entre outras informações, com a finalidade de facilitar o controle social e permitir a avaliação da administração atual, bem como acompanhar a evolução dos serviços públicos ao longo do tempo (ZUCCOLOTTO; TEIXEIRA; RICCIO, 2015).

Nesse contexto, transparência, além de ser princípio do governo aberto, diz respeito à construção da accountability. Assim, considera-se transparência uma prerrogativa tanto para o fortalecimento do governo aberto quanto para a accountability. Esse é o entendimento de Kim et al. (2005), que consideram que transparência é o eixo central para a boa governança e prérequisito essencial para accountabilitity entre Estado e cidadão. 
Ressalta-se, entretanto, que, apesar de o conceito de governo aberto já ter sido introduzido no Brasil pelo Governo Federal, a sociedade ainda fica à mercê do compromisso ou da responsabilidade de gestores e organizações públicas, e dos órgãos que fiscalizam disponibilização e compartilhamento de informações transparentes e compreensíveis sobre as ações governamentais que desenvolvem.

Assim, o gestor público é peça-chave para o nível de transparência da informação pública, pois dele virão incentivos que estimulam ou inibem a divulgação da informação que influencia tais níveis de transparência (STECCOLINI, 2002).

\section{GOVERNO ELETRÔNICO}

Um ambiente onde haja mais aproximação entre cidadãos e Estado é fundamental para promover a accountability numa sociedade. Nesse sentido, acredita-se que, por meio das tecnologias de informação e comunicação, o Estado pode propiciar esse ambiente, disponibilizando canais de relacionamento entre governo e população, serviços para a sociedade e informações. Nesse entendimento, a internet representa elemento importante de interação entre governo e cidadãos (JONG; LENTZ, 2006).

Nessa perspectiva, Diniz et al. (2009) asseveram que o uso dessas tecnologias no ambiente público evoluiu para o que hoje se chama de "governo eletrônico" (e-gov), que tem como princípio a utilização das modernas TIC para democratizar o acesso à informação, ampliar discussões e dinamizar a prestação de serviços públicos com eficiência e efetividade.

Domínguez e Corojan (2013) distinguiram duas correntes principais acerca do tema: a primeira se refere ao governo eletrônico como melhoria técnica e instrumental dos processos administrativos, ou seja, concebe-o como o uso da tecnologia e da internet para melhorar acesso e entrega de informação governamental aos cidadãos, às empresas, aos empregados do governo e a outros organismos, e melhorar a qualidade dos serviços. Já a segunda trata o governo eletrônico como transformação mais profunda, que abrange muito mais do que a melhora instrumental e técnica. Sob o ponto de vista dessa corrente, governo eletrônico se apresenta como modificação da cultura de governo e da forma de governar.

Para Ruediger (2002), o governo eletrônico tem disposição para prover serviços que seriam uma simplificação do e-gov, que, por sua vez, seria apenas um mecanismo de oferta de serviços pontuais ao cidadão. Ou seja, para o Estado, o desenvolvimento do governo eletrônico se torna veículo do governo a serviço da população, utilizado para disponibilizar 
LACERDA, S. M. P.; HELAL, D. H. Governo aberto, transparência e governo eletrônico nas câmaras municipais paraibanas: um estudo multicaso

informações e prestação de serviços online de interesse mais governamental do que para fomentar a participação da sociedade (AIKINS; KRANE, 2010).

O ideal, segundo Ruediger (2002), seria servir como uma arena cívica, isto é, espaço favorável à dialética crítica, ferramenta de capacitação política da sociedade. Dessa forma, ter-se-ia espaço para que a sociedade pudesse discutir politicamente com seus representantes, em busca de seu objetivo comum, o bem-estar ou desenvolvimento igualitários, que todos têm direito de obter, e o Estado tem a obrigação de propiciar.

Pinho (2008), por outra parte, acredita que o governo eletrônico tem potencial enorme de transformação, desde que haja direcionamento político e transparente na participação popular, uma vez que, conforme Braga e Gomes (2016) há uma correlação entre desenvolvimento do governo eletrônico e participação eletrônica.

Pinho (2008), contudo, lembra que as efetivas possibilidades do governo eletrônico devem ser relativizadas ante um contexto das forças de dominação e de poder, que também usam essas tecnologias para manter seu status de dominação.

Para o autor, o governo eletrônico tem se concretizado por meio da criação de portais governamentais. Raupp e Pinho (2013, p. 773) entendem que é por intermédio desses "portais governamentais que os governos mostram sua identidade, seus propósitos, suas realizações, disponibilizam serviços e informações, facilitando a realização de negócios e o acesso à consulta por parte dos cidadãos no sentido de buscar suas necessidades".

Zurra e Carvalho (2008) enunciam que há diferença entre os portais governamentais dos Poderes Executivo e Legislativo, principalmente no que se refere à disponibilização de informações, uma vez que, no Legislativo, não há padrão do que deve constar nesses portais e fica a critério do presidente do parlamento escolher informações que estarão disponíveis para o público.

Contribuindo para o debate, Raupp e Pinho (2011) lembram que as câmaras municipais brasileiras vivem, majoritariamente, em regime patrimonialista. Para Pinho (2008), o Poder Legislativo local que se insere neste contexto orienta-se mais para a prestação de serviços aos governantes do que para a sociedade. Nessa perspectiva, o agente político (vereador) fica confinado ao papel de atendente de necessidades individuais privadas, e isso resulta no clientelismo, adjudicador de uma relação pública-privada (corrupção) que compreende a forma de estabelecer controle sobre recursos políticos.

Lemos e Lévy (2009) acreditam, contudo, que a adoção tecnológica no âmbito do Poder Legislativo pode simplificar atividades administrativas e reduzir custos; possibilitar que 
informações e processos legislativos sejam mais transparentes para a sociedade e fomentar a participação do cidadão para dialogar e deliberar a agenda política ao lado do governo.

Por fim, Santos et al. (2013) acreditam ser necessária a avaliação constante dos portais governamentais, buscando implementar devidos ajustes, de suma importância para que os sites cumpram o propósito de informar e garantir a plena transparência na execução das políticas governamentais.

Assim, para entender como se encontra o estágio das ações de um projeto de governo eletrônico, Hiller e Bélanger (2001) propuseram um quadro referencial que aponta em qual orientação e etapa determinada a administração pública se encontra no âmbito de implementação de ferramentas de governo eletrônico.

O quadro conceitual referido (Quadro 1) traz etapas de governo eletrônico que descrevem e integram a relação única entre o governo e seus componentes variados e identifica e aplica restrições globais que afetam o exercício do governo eletrônico em cada etapa (HILLER; BÉLANGER, 2001).

\begin{tabular}{|c|c|c|c|c|}
\hline Etapa 1 & Etapa 2 & Etapa 3 & Etapa 4 & Etapa 5 \\
\hline Informação & $\begin{array}{c}\text { Comunicação em } \\
\text { duas vias }\end{array}$ & Transações & Integração & $\begin{array}{c}\text { Participação } \\
\text { política }\end{array}$ \\
\hline
\end{tabular}

Quadro 1 - Quadro de referência de orientação e estágio de governo eletrônico Fonte: Adaptado de Hiller e Bélanger (2001) e Moon (2002).

- $\quad$ Etapa 1 - Informação: forma mais básica de governo eletrônico; usa tecnologia da informação (TI) para comunicar; os portais governamentais procuram fornecer informações e dados atualizados e precisos; é relacionado com eficiência interna e projeto organizacional para que a informação tenha valor.

- $\quad$ Etapa 2 - Comunicação em duas vias: os portais governamentais permitem que cidadãos se comuniquem com o governo e façam pedidos de mudanças simples ou específicas; há acesso a formulários e preenchimento de requisições para serviços; a informação não é devolvida imediatamente, mas enviada por via impressa ou e-mail.

- $\quad$ Etapa 3 - Transações: o governo permite serviço online e transações financeiras que substituem funcionários através de interface de autosserviço; os cidadãos renovam licenças, pagam multas, solicitam ajuda financeira etc.; o interesse pelos serviços online aumenta, e o governo tem consciência da limitação dos serviços e busca melhorias.

- $\quad$ Etapa 4 - Integração: analisada sob duas formas (intergovernamental ou vertical e intragovernamental ou horizontal) para reforço de eficiência, facilidade de utilização e eficácia; ocorre com integração entre órgãos, funcionários e prestadores de serviços. 
- $\quad$ Etapa 5 - Participação política: promoção da participação política em que os portais governamentais incluem votação, fóruns públicos e pesquisas de opinião para interação. É importante frisar que as etapas têm o propósito de atuar como componentes complementares, não sendo, necessariamente, mutuamente exclusivos ou estágios consecutivos.

\section{METODOLOGIA}

Esta pesquisa adota o método misto (SAMPIERI; COLLADO; LUCIO, 2006), sendo empregada a estratégia explanatória sequencial (CRESWELL, 2009) em duas etapas, sendo a primeira quantitativa e, a segunda, qualitativa.

Para a seleção das câmaras municipais a ser estudadas na etapa quantitativa, foram estabelecidos os seguintes critérios:

1) Municípios com mais de 10.000 habitantes. A Lei $n^{\circ} 12.527 / 2011$, art. $8^{\circ}, \S 4$, assim menciona: "Municípios com população com até 10.000 (dez mil) habitantes são dispensados da divulgação obrigatória na internet (BRASIL, 2011);

2) O município paraibano deve possuir portais eletrônicos oficiais de suas respectivas câmaras municipais (Poder Legislativo), subentendendo que site oficial é aquele com domínios “pb.gov.br” ou "pb.leg.br";

3) Após aplicação de tais critérios, chegou-se a amostra de 67 municípios, que foram divididos em cinco grupos, a partir de percentis de $20 \%$ com base no tamanho populacional, conforme dados do Instituto Brasileiro de Geografia e Estatística (IBGE). Desse montante, foram selecionados seis municípios em cada grupo, perfazendo trinta.

$\mathrm{Na}$ parte qualitativa, selecionaram-se seis municípios dos trinta da etapa anterior, considerando as duas principais cidades do estado (tipicidade) e um município de cada um dos outros quatro grupos populacionais (acessibilidade). Os municípios selecionados nessa etapa estão apresentados no quadro a seguir.

\begin{tabular}{|c|c|}
\hline TIPICIDADE & ACESSIBILIDADE \\
\hline João Pessoa & Arara \\
\hline Campina Grande & Areia \\
\hline & Alhandra \\
\hline & Taperoá \\
\hline
\end{tabular}

Fonte: Dados da pesquisa. 
Para a coleta de dados na parte quantitativa foi utilizado o instrumento do Ministério da Transparência, Fiscalização e Controladoria-Geral da União denominado checklist Escala Brasil Transparente (checklist EBT). Trata-se de métrica que prioriza a mensuração da efetividade da transparência passiva com doze quesitos que cobrem aspectos da regulamentação do acesso à informação e da existência do Serviço de Informação ao Cidadão (SIC), que contemplam a nova obrigação advinda da Lei de Acesso à Informação (LAI) (BRASIL, 2016).

Adicionalmente, com o propósito de atingir o objetivo de analisar a colaboração e a

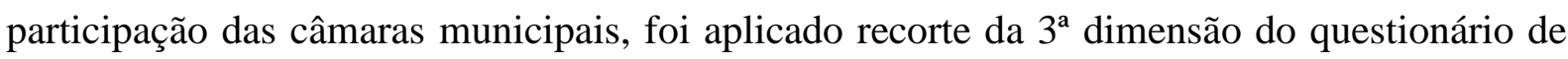
Amorim e Almada (2014), cujo propósito é avaliar as informações apresentadas pelo portal, com a finalidade de dar à sociedade esclarecimentos e serviços de estrutura e funcionamento do município, legislações, modos e canais de participação no governo, programas e projetos realizados em andamento e em discussão, acompanhamento da execução orçamentária, financeira e administrativa, além dos meios de manutenção do diálogo e atendimento das demandas encaminhadas pelo usuário.

Para classificar as câmaras municipais foi empregado o recorte do quadro de referência de Hiller e Belánger (2001), na perspectiva externa do tipo governo/transação com os cidadãos, uma vez que se aproxima das ações desenvolvidas pela câmara municipal da cidade aos munícipes, conforme ilustrado no Quadro 3.

\begin{tabular}{|c|c|c|c|c|c|}
\hline \multirow{3}{*}{$\begin{array}{c}\text { Perspectiva } \\
\text { externa }\end{array}$} & \multirow{2}{*}{$\begin{array}{l}\text { Tipo de } \\
\text { interação }\end{array}$} & Estágio 1 & Estágio 2 & Estágio 4 & Estágio 5 \\
\hline & & Informação & $\begin{array}{c}\text { Com. em } \\
\text { duas vias }\end{array}$ & Integração & Part. Política \\
\hline & $\begin{array}{l}\text { Governo/ } \\
\text { Transação } \\
\text { com } \\
\text { cidadãos }\end{array}$ & $\begin{array}{l}\text { Regulamentos } \\
\text { na internet }\end{array}$ & $\begin{array}{l}\text { Pedidos de } \\
\text { informação } \\
\text { via e-SIC }\end{array}$ & $\begin{array}{l}\text { Regulamentação } \\
\text { que abrange } \\
\text { poderes } \\
\text { municipais }\end{array}$ & $\begin{array}{l}\text { Inserir comentários por } \\
\text { meio da internet }\end{array}$ \\
\hline $\begin{array}{c}\text { Tecnologias } \\
\text { utilizadas }\end{array}$ & & $\begin{array}{l}\text { Tecnologias web } \\
\text { básicas, fóruns }\end{array}$ & E-mail & $\begin{array}{l}\text { Integração das } \\
\text { tecnologias } \\
\text { requeridas nos } \\
\text { estágios } 1,2 \text { e } 3\end{array}$ & $\begin{array}{l}\text { Infraestrutura de chaves- } \\
\text { públicas, salas de } \\
\text { comunicação, interfaces } \\
\text { mais sofisticadas }\end{array}$ \\
\hline
\end{tabular}

Quadro 3 - Recorte do quadro de referência de orientação e estágio de governo eletrônico Fonte: Adaptado de Hiller e Bélanger (2001) e, Moon (2002).

Dessa forma, utilizando quesitos do checklist EBT e do questionário de acompanhamento e interação, os dados foram organizados conforme conceitos de informação, comunicação em duas vias - integração e participação social - e alocados em seus respectivos estágios. Entre eles, evidencia-se o de participação social, no qual a câmara municipal estará, 
caso atenda aos dois quesitos (plataforma deliberativa e participação em redes sociais) (Quadro 4).

\begin{tabular}{|c|c|c|}
\hline $\begin{array}{l}\text { Estágio de Governo } \\
\text { Eletrônico }\end{array}$ & Checklist EBT & Acompanhamento e interação \\
\hline Estágio 1 - Informação & $\begin{array}{l}\text { O regulamento localizado na página } \\
\text { eletrônica }\end{array}$ & $\begin{array}{lr}\text { Instrumentos } & \text { para } \\
\text { acompanhamento dos } & \text { processos } \\
\text { legislativos } & \end{array}$ \\
\hline $\begin{array}{l}\text { Estágio } 2 \text { - Comunicação em } \\
\text { duas vias }\end{array}$ & $\begin{array}{l}\text { Há alternativa de enviar pedidos de } \\
\text { forma eletrônica ao SIC?; pontos de } \\
\text { resposta no prazo }\end{array}$ & \\
\hline Estágio 3 - Integração & $\begin{array}{l}\text { Tipo legal da regulamentação, portanto } \\
\text { que seja Lei Municipal. }\end{array}$ & \\
\hline Estágio 4 - Participação social & & $\begin{array}{l}\text { Debate prévio (plataformas } \\
\text { deliberativas); } \\
\text { participação em redes sociais }\end{array}$ \\
\hline
\end{tabular}

Quadro 4 - Questões utilizadas para classificar os estágios das câmaras municipais Fonte: Dados da pesquisa.

$\mathrm{Na}$ etapa qualitativa, recorreu-se à entrevista semiestruturada, com vistas a compreender os significados atribuídos pelos entrevistados a questões e situações relacionados ao tema e por ser adequada quando há interesse de compreender o mundo dos entrevistados e o que utilizam para basear seus pontos de vista (GODOY, 2010).

Foram feitas entrevistas nas câmaras municipais das seis cidades selecionadas. Os sujeitos da pesquisa foram escolhidos com base na Lei $\mathrm{n}^{\circ} 12.527 / 2011$, cujo art. 40 prevê a figura denominada "Autoridade de Monitoramento", que tem responsabilidade de implementar e assegurar o funcionamento da LAI. Essa figura só é obrigatória no Governo Federal. Todavia, conforme o Ministério da Transparência, Fiscalização e ControladoriaGeral da União, "Estados e Municípios não estão impedidos de reproduzir, adaptar ou até mesmo ampliar as funções de tal entidade, em seus normativos" (BRASIL, 2013, p. 25). Assim, escolheu-se como sujeitos desta pesquisa Autoridades de Monitoramento e Presidentes das Câmaras Municipais selecionadas.

No que se refere à análise dos dados quantitativos, fez-se uso de estatísticas descritivas e análise univariada para evidenciar as ações das Câmaras Municipais em relação à regulamentação, transparência, participação e colaboração, por meio dos portais governamentais. Na parte qualitativa, empregou-se a análise de conteúdo de Bardin (2011), organizada em três fases: 1) pré-análise; 2) exploração do material; e 3) tratamento, inferência e interpretação dos dados. 


\section{RESULTADOS E DISCUSSÃO}

A classificação dos estágios das câmaras municipais, de acordo com o quadro de referência de Hiller e Bélanger (2001), foi feita conforme critérios estabelecidos na pesquisa apresentados no Quadro 4. Os resultados estão resumidos no Quadro 5.

\begin{tabular}{|c|l|}
\hline ETAPA & \multicolumn{1}{c|}{ CIDADES } \\
\hline Informação & $\begin{array}{l}\text { João Pessoa; Campina Grande; Patos; Sousa; Cajazeiras; Cabaceiras; Alagoa Grande; } \\
\text { Solânea; Itabaiana; Ingá; Alhandra; Remígio; Araçagi; Bayeux; Pocinhos; Sumé; Coremas; } \\
\text { Taperoá; Teixeira; Tavares; Arara; Mogeiro; Lucena; Pilar e Dona Inês }\end{array}$ \\
\hline $\begin{array}{c}\text { Comunicação } \\
\text { em duas Vias }\end{array}$ & $\begin{array}{l}\text { João Pessoa; Campina Grande; Patos; Cajazeiras; Cabaceiras; Solânea; Itabaiana; Areia; } \\
\text { Itaporanga; Araçagi; Bayeux; Pocinhos; Sumé; Coremas; Taperoá; Tavares; Arara; Lucena; }\end{array}$ \\
\hline Integração & João Pessoa; Alagoa Grande; Areia; Itaporanga; Pocinhos e Manaíra \\
\hline $\begin{array}{c}\text { Participação } \\
\text { Política }\end{array}$ & $\begin{array}{l}\text { João Pessoa; Campina Grande; Patos; Sousa; Cajazeiras; Pedras de Fogo; Solânea; } \\
\text { Remígio; Pocinhos; Teixeira; Arara; Dona Inês }\end{array}$ \\
\hline
\end{tabular}

Quadro 5 - Maturação do governo eletrônico das câmaras municipais da Paraíba

Fonte: Dados da pesquisa.

A seguir foram realizadas discussões a respeito dos principais resultados de cada estágio de maturação do governo eletrônico.

\subsection{Informação}

O primeiro estágio representa informações e tecnologias básicas. De acordo com Bélanger e Hiller (2006), a informação disseminada nesse estágio é uma forma simplista de governo eletrônico, na qual governos postam informações no website para a população. Além disso, portais governamentais procuram fornecer dados e informações atualizados e precisos. Câmaras municipais que estariam nesse estágio foram as que compartilharam em seu portal a Lei de Acesso à Informação Municipal e os instrumentos para acompanhar processos legislativos (Tabelas 1 e 2).

Tabela 1 - Regulamentação localizada na página da Câmara Municipal

\begin{tabular}{l|c|c|c|c}
\hline $\begin{array}{l}\text { O regulamento foi localizado na página } \\
\text { eletrônica? }\end{array}$ & Frequência & $\begin{array}{c}\text { Frequência } \\
(\%)\end{array}$ & $\begin{array}{c}\text { Frequência } \\
\text { acumulativa }\end{array}$ \\
\hline Não & 28 & 93,3 & 93,3 \\
\hline Sim & 2 & 6,7 & 100,0 \\
\hline Total & $\mathbf{3 0}$ & $\mathbf{1 0 0 , 0}$ & \\
\hline
\end{tabular}

Fonte: Dados da pesquisa. 
LACERDA, S. M. P.; HELAL, D. H. Governo aberto, transparência e governo eletrônico nas câmaras municipais paraibanas: um estudo multicaso

Tabela 2 - Acompanhamento do processo legislativo

\begin{tabular}{l|c|c|c}
\hline Acompanhamento do processo legislativo & Frequência & Frequência $(\boldsymbol{\%})$ & Frequência acumulada \\
\hline Não existe & 4 & 13,3 & 13,3 \\
\hline Regular & 23 & 76,7 & 90,0 \\
\hline Muito bom & 3 & 10,0 & 100,0 \\
\hline Total & $\mathbf{3 0}$ & $\mathbf{1 0 0 , 0}$ & \\
\hline
\end{tabular}

Fonte: Dados da pesquisa.

Assim, os dados revelaram que apenas duas câmaras municipais compartilharam a LAI Municipal em seus portais governamentais para que qualquer cidadão possa consultá-la. As outras cidades dispõem de instrumentos para que a população tenha acesso às leis municipais; observou-se, contudo, que essa disponibilização não ocorre de forma atualizada.

A falta de disponibilização da LAI no portal governamental das câmaras municipais paraibanas pode ter ocorrido em função de não haver obrigatoriedade por lei de disponibilizar essa informação no portal.

\subsection{Comunicação em duas vias}

Nesse estágio, por meio dos portais governamentais, cidadãos podem se comunicar com o governo; porém a informação não é devolvida imediatamente, mas enviada por via impressa ou e-mail (MOON, 2002).

Então, para garantir que as informações solicitadas pela sociedade sejam atendidas, a Lei de acesso à informação prevê que órgãos públicos criem o Serviço de Informação ao Cidadão (SIC) tanto na forma física quanto na eletrônica ou virtual, denominada E-SIC. A partir de tal serviço, a sociedade pode encaminhar pedidos de acesso à informação para órgãos e entidades dos poderes estatais.

A pesquisa relacionou a comunicação em duas vias (Estágio 2) com a existência e o funcionamento do E-SIC, conforme se evidencia na Tabela 3.

Tabela 3 - Alternativa de enviar pedidos pelo E-SIC

\begin{tabular}{l|c|c|c}
\hline $\begin{array}{l}\text { Alternativa de enviar pedidos de forma } \\
\text { eletrônica ao SIC }\end{array}$ & Frequência & Frequência (\%) & $\begin{array}{c}\text { Frequência } \\
\text { acumulada }\end{array}$ \\
\hline Não & 10 & 33,3 & 33,3 \\
\hline Sim & 20 & 66,7 & 100,0 \\
\hline Total & $\mathbf{3 0}$ & $\mathbf{1 0 0 , 0}$ & \\
\hline
\end{tabular}

Fonte: Dados da pesquisa. 
Os resultados indicam que apesar de 66,7 \% das câmaras municipais apresentarem a alternativa de enviar pedidos pelo E-SIC, tais sistemas não funcionam adequadamente: apenas $16,7 \%$ efetivamente responderam ao usuário.

Tabela 4 - Prazos de respostas

\begin{tabular}{l|c|c|c}
\hline Pontos de respostas no prazo & Frequência & Frequência (\%) & Frequência acumulada \\
\hline Sem alternativa de envio & 10 & 33,3 & 33,3 \\
\hline Sim & 5 & 16,7 & 50,0 \\
\hline Não & 15 & 50,0 & 100,0 \\
\hline Total & $\mathbf{3 0}$ & $\mathbf{1 0 0 , 0}$ & \\
\hline
\end{tabular}

Fonte: Dados da Pesquisa.

Tal diferença pode ser atribuída ao grau de importância que os gestores dão ao E-SIC. As entrevistas em João Pessoa e em Arara indicaram a influência da vontade política e da gestão para concretizar esse serviço para o cidadão.

\begin{abstract}
A câmara municipal de Arara através da sua nova gestão, do atual presidente professor Luizinho, procurou desde o início dar essa nova cara, essa nova cara de inovação. Primeiro, buscamos e fomos atrás da possibilidade de abrir um e-mail, onde fosse a casa da Câmara Municipal na internet (Câmara Municipal de Arara, 2017, p.04).

[...] a gente implantou o E-SIC. O E-SIC é muito bom, porque dentro dele a gente conseguiu regulamentar um fluxo de informações, certo? Como a estrutura da Câmara não é uma estrutura muito grande, a gente sempre teve o cuidado de chegar um questionamento e resolveu o mais rápido possível porque se não resolver no outro dia estará no rádio - Eu pedi essa informação à Câmara e a Câmara não deu (Rs). Então, a lei foi bom porque ela deu um prazo para gente de 30 dias podendo dilatar para 10 dias (Câmara Municipal de João Pessoa, 2017, p.42).
\end{abstract}

Nossa pesquisa identificou que a maior parte das câmaras pesquisadas não respondeu às solicitações das informações, indicando fragilidade no serviço. Acredita-se que um dos fatores do não funcionamento está relacionado ao tamanho da cidade. Entrevistas indicaram que em cidades menores, os cidadãos preferem utilizar o serviço in loco, ou seja, vão à casa legislativa e pedem por meio de ofício:

Eles (a população) preferem oficializar aqui à Casa e pedir através de ofício. Inclusive, a gente pode mandar até por e-mail... A gente tá digitalizando tudo que é de documento aqui, as leis, os decretos, tudo, pra já justamente facilitar nessa parte, porque toda vez que chega uma pessoa aqui... (Câmara Municipal de Areia, 2017, p.23). 
Além disso, é interessante destacar que a comunicação em duas vias, nesta pesquisa, caracterizada pelo E-SIC, possibilita a interação entre governo e cidadãos, porém, de forma mais simples, porque a tecnologia utilizada é o correio eletrônico.

\subsection{Integração}

Nesse estágio, segundo Moon (2002), o governo procura integrar vários serviços de governo vertical (integração intergovernamental) e horizontalmente (integração intragovernamental) para reforçar a eficiência, facilitar a utilização e promover eficácia. Nessa perspectiva, buscou-se verificar a integração intragovernamental ou horizontal. Portanto, ficou definido que a Lei de Acesso à Informação Municipal (tipo de norma que abrange os Poderes Executivo e Legislativo) disponível no portal governamental da câmara seria o indicador para determinar se a câmara municipal contemplava o conceito de integração do quadro de Hiller e Bélanger (2001).

Observou-se que apenas sete câmaras municipais pesquisadas regulamentaram a LAI, conforme a Tabela 5 .

Tabela 5 - Regulamentação da LAI pela Câmara Municipal

\begin{tabular}{l|c|c|c}
\hline O ente regulamentou a LAI? & Frequência & Frequência $(\%)$ & $\begin{array}{c}\text { Frequência } \\
\text { acumulativa }\end{array}$ \\
\hline Não & 23 & 76,7 & 76,7 \\
\hline Sim & 7 & 23,3 & 100,0 \\
\hline Total & $\mathbf{3 0}$ & $\mathbf{1 0 0 , 0}$ & \\
\hline
\end{tabular}

Fonte: Dados da pesquisa.

Nesse contexto, constatam-se, a partir dos trechos a seguir, tentativas de as câmaras municipais integrarem o acesso à informação entre Poder Executivo e Legislativo:

Acontece que muitas pessoas que vem procurar documentos; elas vêm sem saber informações de nada como funciona e vêm fisicamente pedir, exemplo: cópia de lei, cópias de projetos ou de contratos até aqueles que são da prefeitura, mas como nós temos algumas partes do balancete e o que for disponível, mesmo sendo da prefeitura, nós tentamos disponibilizar como folha de pagamentos dentre outras coisas, o pessoal vem procurar fisicamente (Câmara Municipal de Arara, 2017, p.06).

A gente digitalizou todas as leis, só que a gente digitou e não digitalizou... Tem muita gente que quer a lei, mas quer a lei originária com assinatura do prefeito e com carimbo da aprovação... teve uma pessoa que perguntou a gente sobre o estatuto do servidor do município executivo, a gente conseguiu resgatar todas as leis desde 1947, só que as regulamentações é feita através de decretos, só que os decretos a gente tinha uma dificuldade de fornecer o estatuto do servidor (Câmara Municipal de João Pessoa, 2017, p.45). 
LACERDA, S. M. P.; HELAL, D. H. Governo aberto, transparência e governo eletrônico nas câmaras municipais paraibanas: um estudo multicaso

Esses discursos indicam que a principal forma de integração é a disponibilidade das leis, dos decretos etc., tanto do Executivo quanto do Legislativo, principalmente a Lei de Acesso à Informação Municipal. Os resultados indicaram que os municípios que regulamentaram a LAI foram João Pessoa, Alagoa Grande, Areia, Pocinhos, Itaporanga e Manaíra. Porém, desses seis, somente dois - João Pessoa e Areia - disponibilizaram as leis em seus devidos portais.

\subsection{Participação social}

Nesta subseção, foram indicados para o estágio de participação social os municípios que tiveram como critério "localizado" nos itens: debate prévio (plataformas deliberativas) ou participação em redes sociais (Tabelas 6 e 7).

Tabela 6 - Disponibilidade de plataformas deliberativas

\begin{tabular}{l|c|c|c}
\hline $\begin{array}{l}\text { Debate prévio } \\
\text { deliberativas) }\end{array}$ & Frequência & Frequência (\%) & $\begin{array}{l}\text { Frequência } \\
\text { acumulada }\end{array}$ \\
\hline Não localizado & 26 & 86,7 & 86,7 \\
\hline Localizado & 4 & 13,3 & 100,0 \\
\hline Total & $\mathbf{3 0}$ & $\mathbf{1 0 0 , 0}$ & \\
\hline
\end{tabular}

Fonte: Dados da pesquisa.

Tabela 7 - Redes sociais das câmaras municipais

\begin{tabular}{l|c|c|c}
\hline Participação em redes sociais & Frequência & Frequência (\%) & $\begin{array}{c}\text { Frequência } \\
\text { acumulada }\end{array}$ \\
\hline Não localizado & 18 & 60,0 & 60,0 \\
\hline Localizado & 12 & 40,0 & 100,0 \\
\hline Total & $\mathbf{3 0}$ & $\mathbf{1 0 0 , 0}$ & \\
\hline
\end{tabular}

Fonte: Dados da pesquisa.

Assim, conforme critérios pré-estabelecidos, doze das trinta câmaras municipais incluem, nos portais governamentais, espaços destinados a apoiar ou incentivar participação de cidadãos. Para a câmara municipal de Arara/PB, essa participação traz mais transparência e eficiência na gestão, e a rede social, como Facebook, é considerada canal relevante de diálogo com a sociedade.

Ruediger (2002) lembra que o governo eletrônico tem disposição que ele chama de simplificação do E-gov. O autor refere que o ideal seria servir como arena cívica, ou seja, espaço favorável à dialética crítica, ferramenta de capacitação política da sociedade. 
No cenário paraibano, evidenciam-se as duas formas de governo eletrônico de Ruediger (2002). A constatação de simplificação de governo eletrônico é encontrada especialmente na câmara municipal de Areia.

\begin{abstract}
[...] eu não vou deixar, no site, as pessoas poderem comentar, nem o vídeo e nem as fotos". Por quê? Na minha visão [responsável pelo portal] e ele [presidente da câmara municipal de Areia] concordou na época comigo, foi o seguinte: você imagina que tamo numa cidade muito pequena, e aí eu coloco um vídeo e aí alguém se acha no direito de denegrir alguém como acontece hoje muito no Facebook... Você coloca um vídeo que você fez ou publicou, promovendo alguma coisa, alguém discordar das suas opiniões e começar uma discussão que não vai levar a lugar nenhum... Tem os e-mails dos vereadores e aí ele pode entrar em contato com os vereadores um por um, entendeu? (Câmara Municipal de Areia, 2017, p.26).
\end{abstract}

De outra parte, as câmaras de João Pessoa e Campina Grande foram as que mais se aproximaram do conceito de governo eletrônico ideal de Ruediger (2002).

A câmara municipal de João Pessoa criou programa denominado "João + Pessoas", um canal que surgiu de reuniões de planejamento anual para aproximar cada pessoa da cidade. Já a câmara municipal de Campina Grande buscou informar a sociedade por meio das redes sociais, procurando usar a que estiver em evidência:

Redes sociais, eu acho que o primeiro, senão me engano foi o Twitter. Aí começamos os serviços: abrirmos Twitter para todos os vereadores, abrimos Twitter institucional. A partir daí começamos a fazer uma narrativa das sessões através do Twitter colocando algumas mensagens e incentivando aos vereadores a colocarem isso... Foi crescendo na medida em que as redes sociais elas iam também crescendo e direcionáveis. Hoje nós temos aqui Whatsapp, nós temos o plenário em foco, que foi criado por nós aqui; ele tem um boletim e tem também o plenário em foco no Facebook, no Twitter, no Whatsapp. No Whatsapp nós temos algumas estagiárias de comunicação dizendo em tempo real o que está acontecendo (Câmara Municipal de Campina Grande, 2017, p.16).

\title{
7 CONSIDERAÇÕES FINAIS
}

Em termos gerais, a pesquisa colabora com academia e gestores públicos das câmaras municipais, por trazer compreensão de como o órgão e seus respectivos gestores estão institucionalizando a Lei de Acesso à Informação e incentivando a participação da sociedade nos espaços políticos. Em termos acadêmicos, evidencia, no contexto brasileiro, uma realidade percebida em outros contextos (ZURRA; CARVALHO, 2008; RAUPP; PINHO, 2011; 2013). Isso quer dizer que, apesar da evolução em relação à legislação ao acesso à informação e democracia, o Poder Legislativo local paraibano não contribui efetivamente para o desenvolvimento do governo aberto. 
Os resultados indicam que das trinta câmaras municipais pesquisadas, 23 não regulamentaram a Lei de Acesso à Informação. Isso demonstra que, embora o Estado incentive e estabeleça normatização para divulgar a informação, as Câmaras Municipais paraibanas selecionadas estão muito aquém do que seria considerado ideal para que houvesse quebra do paradigma da cultura do sigilo.

Outra evidência está relacionada à divulgação da Lei de Acesso à Informação nos portais governamentais. Os resultados da pesquisa indicaram que, das trinta Câmaras Municipais pesquisadas, apenas em duas foi possível encontrar normatização municipal em seu portal.

A pesquisa buscou identificar câmaras que buscam transparência e governo eletrônico em conjunto, como prerrogativa para o fortalecimento de accountability e governo aberto. Neste contexto, destaca-se que a câmara municipal de Arara foi a única em que se pode atribuir excelência na questão, uma vez que se apresentam as cinco etapas de maturação do governo eletrônico, logo, com mais possibilidades de ter accountability forte, e se aproximando ao que se entende por governo aberto. Sobre tal aspecto, Sandoval-Almazan e Gil-Garcia (2012) entendem que portais governamentais podem servir como instrumentos de auxílio na interação, participação e colaboração entre os diversos atores governamentais e não governamentais e representar componente-chave dentro da rede de conhecimento e atuação do setor público, a ponto de, em longo prazo, instituir novo modelo de governança.

Ao identificar as principais características dos portais dos Poderes Legislativos paraibanos, constatou-se que a particularidade preponderante nas câmaras municipais paraibanas pesquisadas é a disponibilização da informação. Nesse sentido, portais governamentais são simplistas e servem como mural de recados, e accountability e governo aberto ainda são mais uma retórica do que, propriamente, uma realidade.

Acredita-se, assim, que as câmaras municipais paraibanas têm grande desafio na implementação tanto do governo aberto quanto da transparência, uma vez que há apenas uma que atende a LAI, por completo. Outro desafio refere-se à implementação de uma cultura de transparência, sendo necessário tempo para sua institucionalização.

Achados da pesquisa demonstram que os portais governamentais das câmaras municipais pesquisadas são essencialmente fontes de informações, que há escassez nas interações (estágio 3) e pouca participação e colaboração entre o cidadão e o Poder Legislativo municipal. Apesar de os portais das Câmaras Municipais serem instrumento muito útil para a governança local, o Poder Legislativo municipal não utiliza todo o potencial oferecido pelas TIC. 
Nesse sentido, propõe-se que gestores públicos locais desenvolvam políticas públicas para promover a adoção de ações de transparência, accountability, participação e colaboração, e governo eletrônico, com o intuito de utilizar o portal na Internet municipal como centro de informações de redes públicas de compartilhamento. Isso inclui a participação de atores governamentais e não governamentais que poderiam trocar informações e serviços, participar e colaborar uns com os outros por meio de ferramentas de tecnologias e aplicações integradas (SANDOVAL-ALMAZAN; GIL-GARCIA, 2012).

\title{
OPEN GOVERNMENT, TRANSPARENCY AND ELECTRONIC GOVERNMENT IN THE MUNICIPALITIES OF PARAÍBA - BRAZIL: A MULTICASE STUDY
}

\begin{abstract}
The article seeks to understand how the current stage of transparency and e-government actions in the Municipal Legislative Chamber of Paraíba works. It analyzes, in particular, the access to information, participation and collaboration of society in political and deliberative processes. As a method, the article adopted the mixed approach. The first step was quantitative, based on the verification, in thirty municipal chambers selected from the population size of the municipality, of the effectiveness of passive transparency, through the application of Escala Brasil Transparente, which covers aspects of the regulation of access to information and existence of the Citizen Information Service. In the qualitative section, six Municipal Chambers were selected, where interviews were conducted with the monitoring authorities and their presidents. The results indicated that of the thirty chambers surveyed, 23 did not regulate the Law of Access to Information. Finally, it was identified that the portals of the Paraíba Legislative Chambers are concerned with making information available in a simplistic way, and that accountability and open government are still distant goals.
\end{abstract}

Keywords: Open government. Transparency. E-government.

\section{REFERÊNCIAS}

AIKINS, Stephen Kwamena; KRANE, Dale. Are public officials obstacles to citizen-centered e-government? an examination of municipal administrators motivations and actions. State $\&$ Local Government Review, Las Vegas, v. 42, n. 2, p. 87-103, 2010.

AMORIM, Paula Karini; ALMADA, Maria Paula. E-transparência: proposta de modelo metodológico para avaliação de portais de executivos nacionais. In: ENCONTRO ANUAL DA ANPOCS, 38., 2014, Caxambu. Anais... Caxambu: Anpocs, p. 1-23, 2014.

ANGÉLICO, Fabiano. Lei de acesso à informação pública e seus possíveis desdobramentos à accountability democrática no Brasil. 2012. 133 f. Dissertação (Mestrado em Administração Pública e Governo) - Fundação Getúlio Vargas, São Paulo, 2012. 
BARDIN, Laurence. Análise de conteúdo. São Paulo: Edições 70, 2011.

BÉLANGER, France; HILLER, Janine S. A framework for e-government: privacy implications. Business Process Management Journal, Bingley, v. 12, n. 1, p. 48-60, 2006.

BINGHAM, Lisa Blomgren; FOXWORTHY, Susanna. Collaborative Governance and Collaborating Online. In: Conference: converging and conflicting trens in the public administration of the US, EUROPE, AND GERMANY. 2012, Speyer. Proceedings... Speyer: GRIP, 2012.

BRAGA, Lamartine Vieira; GOMES, Ricardo Corrêa. Participação eletrônica e suas relações com governo eletrônico, efetividade governamental e accountability. Organizações \& Sociedade, Salvador, v. 23, n. 78, p. 487-506, 2016.

BRASIL. Lei n ${ }^{\circ}$ 12.527, de 18 de novembro de 2011. Diário Oficial da União, Brasília, DF, 18 nov. 2011.

BRASIL. CONTROLADORIA-GERAL DA UNIÃO. Manual da Lei de Acesso à Informação para estados e municípios. Brasília, DF: Controladoria-Geral da União, 2013. Disponível em: https://goo.gl/EzRnt8. Acesso em: 30 nov 2017.

BRASIL. Metodologia - checklist escala Brasil transparente (EBT). 3. ed. Brasília, DF: Ministério da Transparência e Controladoria-Geral da União, 2016. Disponível em: https://goo.gl/avHe8M. Acesso em: 8 ago. 2016.

BRESSER-PEREIRA, Luiz Carlos; SPINK, Peter (Orgs). Reforma do Estado e administração pública gerencial. Rio de Janeiro: Fundação Getúlio Vargas, 1998.

COBO, De Cristóbal. Gobierno abierto: de la transparencia a la inteligencia cívica. In: HOFMAN, Andrés; RAMÍREZ-ALUJAS, Álvaro; PEREZNIETO, José Antônio Bojórquez (Coords.). La promessa del gobierno abierto. Ciudad de México: Creative Commons, 2013. p. 101-118.

CRESWELL, Jonh W. Research design. Thousand Oaks, California: Sage, 2009.

CRUZ, Cláudia Ferreira et al. Transparência da gestão pública municipal: um estudo a partir dos portais eletrônicos dos maiores municípios brasileiros. Revista de Administração Pública, Rio de Janeiro, v. 46, n. 1, p. 153-176, 2012.

DINIZ, Eduardo Henrique et al. O governo eletrônico no Brasil: perspectiva histórica a partir de um modelo estruturado de análise. Revista de Administração Pública, Rio de Janeiro, v. 43, n. 1, p. 23-48, 2009.

DOMÍNGUEZ, Eva Campos; COROJAN, Ana. Estado del arte del gobierno abierto: promesas y expectativas. In: Hofman, Andrés; Ramírez-Alujas, Álvaro; Pereznieto, José Antônio Bojórquez. (Coords.). La promessa del gobierno abierto. Ciudad de México: Creative Commons, 2013, p. 119-136. 
LACERDA, S. M. P.; HELAL, D. H. Governo aberto, transparência e governo eletrônico nas câmaras municipais paraibanas: um estudo multicaso

FOX, Jonathan A. The uncertain relationship between transparency and accountability. Development in Practice, New York, v. 17, n. 4-5, p. 663-671, 2007.

GAVELIN, Karen; BURALL, Simon; WILSON, Richard. Open government: beyond static measures. Paris: OECD, 2009.

GODOY, Arilda. Estudo de caso qualitativo. In: Godoi, Christiane. K.; Bandeira-de-Melo, Rodrigo.; Silva, Anielson. B. (Orgs.). Pesquisa qualitativa em estudos organizacionais: paradigmas, estratégias e métodos. São Paulo: Saraiva, 2010.

HILLER, Janine. S.; BÉLANGER, France. Privacy strategies for electronic government. In: Abramson, Mark. A.; Means, Grady. E. (Eds.). E-Government 2001. Lanham: Rowman; Littlefield, 2001, p. 162-198.

JONG, Menno de; LENTZ, Leo. Scenario evaluation of municipal web sites: development and use of an expert-focused evaluation tool. Government Information Quarterly, Amsterdam, v. 23, n. 2, p. 191-206, 2006.

KIM, Pan Suk et al. Toward participatory and transparent governance: report on the sixth global forum on reinventing government. Public Administration Review, Medford, v. 65, n. 6, p. 646-654, 2005.

LEMOS, André; LÉVY, Pierre. O futuro da internet: em direção a uma ciberdemocracia planetária. In: Lévy, Pierre. Ciberdemocracia. Lisboa: Instituto Piaget, 2009.

LIMA-FILHO, Raimundo Nonato et al. Accountability e governo eletrônico: uma análise sobre a participação popular. Pensamento Contemporâneo em Administração, Rio de Janeiro, v. 5, n. 2, p. 17-32, 2011.

MARISCAL, Jacqueline Peschard. Del gobierno abierto a la transparencia proactiva: la experiencia del IFAI en 2011. In: HOFMAN, Andrés; RAMÍREZ-ALUJAS, Álvaro; PEREZNIETO, José Antônio Bojórquez (Coords.). La promessa del gobierno abierto. Ciudad de México: Creative Commons, 2013. p. 27-50.

MENDIETA, Manuel Villoria. El gobierno abierto como subsistema de políticas: una evaluación desde el institucionalismo discursivo. In: HOFMAN, Andrés; RAMÍREZALUJAS, Álvaro; PEREZNIETO, José Antônio Bojórquez (Coords.). La promessa del gobierno abierto. Ciudad de México: Creative Commons, 2013, p. 69-100.

MOON, M. Jae. The evolution of e-government among municipalities: rhetoric or reality? Public Administration Review, Medford, v. 62, n. 4, p. 424-433, 2002.

OPEN GOVERNMENT PARTNERSHIP. Balanço: plano de ação do Brasil na parceria para governo aberto. Brasília, DF: Controladoria-Geral da União, 2013.

PINHO, José Antônio Gomes de. Investigando portais de governo eletrônico de Estados no 
Brasil: muita tecnologia, pouca democracia. Revista de Administração Pública, Rio de Janeiro, v. 42, n. 3, p. 471-493, 2008.

RAMÍREZ-ALUJAS, Álvaro V. Gobierno abierto y modernización de la gestión pública: tendencias actuales y el invitable camino que viene. Reflexiones seminales. Revista Enfoques, Santiago, v. 9, n. 15, p. 99-125, 2011.

RAUPP, Fabiano Maury; PINHO, José Antônio Gomes de. Construindo a accountability em portais eletrônicos de câmaras municipais: um estudo de caso em Santa Catarina. Cadernos EBAPE.BR, Rio de Janeiro, v. 9, n. 1, p. 116-138, 2011.

RAUPP, Fabiano Maury; PINHO, José Antônio Gomes de. Accountability em câmaras municipais: uma investigação em portais eletrônicos. Revista de Administração, São Paulo, v. 48, n. 4, p. 770-782, 2013.

RUEDIGER, Marco Aurélio. Governo eletrônico e democracia: uma análise preliminar dos impactos e potencialidades na gestão pública. Organizações \& Sociedade, Salvador, v. 9, n. 25, p. 29-43, 2002.

SAMPIERI, Roberto Hernández; COLLADO, Carlos Fernández; LUCIO, Maria Del Pilar Baptista. Metodologia de pesquisa. 1. ed. São Paulo: McGraw-Hill, 2006.

SANDOVAL-ALMAZAN, Rodrigo; GIL-GARCIA, José Ramón. Are government internet portals evolving towards more interaction, participation, and collaboration? Revisiting the rhetoric of e-government among municipalities. Government Information Quarterly, Amsterdam, v. 29, n. 1, p. 72-81, 2012.

SANTOS, Paloma Maria et al. Ranking dos tribunais de contas brasileiros: uma avaliação a partir dos padrões web em governo eletrônico. Revista de Administração Pública, Rio de Janeiro, v. 47, n. 3, p. 721-744, 2013.

STECCOLINI, Ileana. Local government annual report: an accountability medium? Milano: SDA Bocconi, 2002.

ZUCCOLOTTO, Robson; TEIXEIRA, Marco Antonio Carvalho; RICCIO, Edson Luiz. Transparência: reposicionando o debate. Revista Contemporânea de Contabilidade, Florianópolis, v. 12, n. 25, p. 137-158, 2015.

ZURRA, Romulo José de Oliveira; CARVALHO, Márcio André de. O E-legislativo como ferramenta de transparência na administração pública brasileira. In: Encontro de Administração Pública e Governança, 3., 2008, Salvador. Anais... Salvador: Anpad.

\section{DADOS DOS AUTORES}

\section{Sérvulu Mário de Paiva Lacerda}

E-mail: servulu@gmail.com 
Currículo Lattes: http://lattes.cnpq.br/2785007219923401

Mestre em Administração pela Universidade Federal da Paraíba (UFPB), especialização em Gestão e Auditoria Pública pelo Instituto de Educação Superior da Paraíba, tecnólogo em Gestão Pública e Bacharel em Administração pela UFPB.

\section{Diogo Henrique Helal}

E-mail: diogohh@yahoo.com.br

Currículo Lattes: http://lattes.cnpq.br/5268265898312612

Doutor em Ciências Humanas, com concentração em Sociologia, pela Universidade Federal de Minas Gerais (UFMG), graduado e mestre em Administração pela Universidade Federal de Pernambuco (UFPB). Pesquisador Adjunto da Fundação Joaquim Nabuco (FUNDAJ/MEC), também Professor Permanente do Programa de Pós Graduação em Administração (PPGA/UFPB) e Professor Titular do Centro Universitário FBV (UniFBV/Adtalem), atuando no Mestrado Profissional em Gestão Empresarial (MPGE) e na graduação. É consultor ad hoc da CAPES (APCN - Mestrados Profissionais) e avaliador ad hoc de projetos submetidos à FACEPE (Fundação de Amparo à Ciência e Tecnologia do Estado de Pernambuco). Tem desenvolvido projetos de pesquisa com financiamento externo (CNPq e FACEPE). Tem experiência na área de Administração e Sociologia, atuando principalmente nos seguintes temas: Gestão de Pessoas e Relações de Trabalho, Desigualdades Sociais, Gestão e Políticas Públicas. 